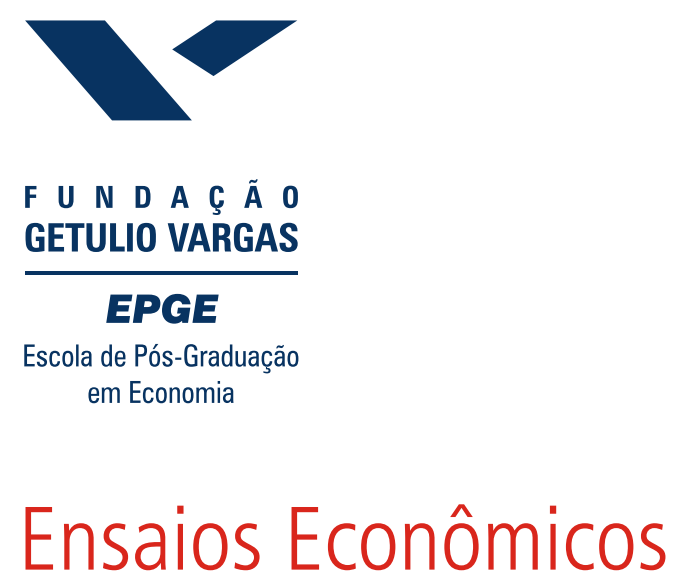

$$
\begin{aligned}
& \text { Escola de } \\
& \text { Pós Graduação } \\
& \text { em Economia } \\
& \text { da Fundação } \\
& \text { Getulio Vargas }
\end{aligned}
$$

Comparing Value-at-Risk Methodologies

Luiz Renato Lima, Breno de Andrade Pinheiro Néri

Novembro de 2006 
Os artigos publicados são de inteira responsabilidade de seus autores. As opiniões neles emitidas não exprimem, necessariamente, o ponto de vista da Fundação Getulio Vargas. 


\title{
Comparing Value-at-Risk Methodologies
}

\author{
Luiz Renato Lima* \\ Breno de Andrade Pinheiro Néri ${ }^{\dagger}$ \\ Graduate School of Economics - Getúlio Vargas Foundation \\ Rio de Janeiro, Brazil
}

October 26, 2006

\begin{abstract}
In this paper, we compare four different Value-at-Risk $(V a R)$ methodologies through Monte Carlo experiments. Our results indicate that the method based on quantile regression with ARCH effect dominates other methods that require distributional assumption. In particular, we show that the non-robust methodologies have higher probability to predict $V a R$ s with too many violations. We illustrate our findings with an empirical exercise in which we estimate $V a R$ for returns of São Paulo stock exchange index, IBOVESPA, during periods of market turmoil. Our results indicate that the robust method based on quantile regression presents the least number of violations.
\end{abstract}

- JEL Classification: C52; C53, G15;

- Keywords: Time Series, Value-at-Risk, Quantile Regression.

\footnotetext{
*E-mail: luizr@fgv.br

${ }^{\dagger}$ E-mail: bneri@fgvmail.br and Homepage: www.fgv.br/aluno/bneri
} 


\section{Introduction}

Every day, financial institutions (like banks) estimate measures of market risk exposure, which are analyzed by the institutions's decision makers. These estimates are also analyzed by internal and external auditors and regulatory agencies, who enforce that those institutions set aside enough capital to cover their risk exposures. This concern about market risk exposure has been increasing since the stock market crash in 1987, when 1 trillion of dollars (23\% drop in value) was lost in a single day, known as the Black Monday. The recent turbulence in emerging markets, starting in Mexico in 1995, continuing in Asia in 1997, and spreading to Russia and Latin America in 1999, has further extended the interest in risk management.

Imprecise measures of risk cause inefficiencies: on one hand, if the measure is too conservative, then too much capital, that could be used in a more profitable way, is set aside; on the other hand, if it is too risky, then it yields a large number of violations, which may lead the institution to bankruptcy. Hence, researching for more and more reliable and accurate measure of risk methodologies is an active and growing literature.

Value-at-Risk $(V a R)$ is probably the most used measure of risk since the 1996 amendment to the Basle Capital Accord which proposed that commercial banks with significant ${ }^{1}$ trade activity could use their own $V a R$ measure to define how much capital they should set aside to cover their market risk exposure, and U.S. bank regulatory agencies could audit the $V a R$ methodology employed by the banks. This amendment was adopted in 1998 (Lopez, 1999) ${ }^{2}$. In Brazil, the article 59 of the resolution $\mathrm{N}^{0}$ 2.829, March 2001, of the Brazilian Central Bank brings "Para os seguimentos de renda fixa e de renda variável deverá ser feito o cálculo do Valor em Risco (VaR) ...", mandating the use of VaR to some markets.

Value-at-Risk is the loss in market value over a given time horizon that is exceeded with probability $\tau$. That is, for a time series of returns $r_{t}$, find $V a R_{t}$ such that

$$
P\left[r_{t}<-V a R_{t} \mid I_{t-1}\right]=\tau,
$$

where $I_{t-1}$ denotes the information set at time $t-1$. From this definition, it is clear that finding a $V a R$ essentially is the same as finding a $100 \tau \%$ conditional quantile. Note that, for convention, the sign is changed to avoid negative number in the $\operatorname{VaR}_{t}(\tau)$ time series. For regulatory purpose, $\tau$ is generally set to $1 \%$. It does not mean that the banks may not estimate $V a R$ s under different significance levels for their risk managers.

Although $V a R$ is a relatively simple concept, robust estimation of it is often ignored in practice. Indeed, one popular approach to estimate $V a R$ assumes

\footnotetext{
${ }^{1}$ Any bank or bank holding company whose trading activity equals greater than 10 percent of its total assets or whose trading activity equals greater than $\$ 1$ billion must hold regulatory capital against their market risk exposure.

${ }^{2}$ Not ony the American banks but also the Brazilian banks use $V a R$ to measure their risk exposure. For example: Unibanco S.A., HSBC Bank Brasil S.A., Banco Real ABN AMRO S.A., Banco do Brasil S.A. and many others.
} 
a conditionally normal return distribution. The estimation of $V a R$ is, in this case, equivalent to estimating conditional volatility of returns. Another popular method is to compute the empirical quantile nonparametrically, for example, rolling historical quantiles or Monte Carlo simulations based on an estimated model $^{3}$.

However, these models are based on restricted assumptions about the distribution of returns. There has been accumulated evidence that portfolio returns (or log returns) are usually not normally distributed. In particular, it is frequently found that market returns display structural shifts, negative skewness and excess kurtosis in the distribution of the time series. This is particularly true in periods of market stress such as the financial crises faced by the Brazilian economy from 1997 to 2000 . These market characteristics suggest that more robust methods are needed to estimate $V a R$.

In this paper, we estimate $V a R$ using a robust method based on quantile regression model that allows for ARCH effect, and compare it to three other nonrobust $\mathrm{VaR}$ methodologies that are based on GARCH type volatility models. It is important to mention that Engle and Manganelli (1999) consider a different quantile regression based method. In particular, they consider an autoregression of the estimated $V a R$ s. Our approach, however, has the advantage of pursuing a well-developed distributional theory which facilitates statistical inference and computational optimization.

We are not the first ones to compute $V a R$ using a quantile regression model that allows for ARCH effect. In fact, Wu and Xiao (2002) used this model to estimate $V a R$ and left-tail measures that were next employed to construct a risk-managed index fund. The performance of the ARCH Quantile method were then evaluated according to the capacity of the risk-managed index fund in tracking the S\&P500 index.

There are, however, other ways to assess the quality of a $V a R$ methodology. In this paper, we follow Engle and Manganelli (2001) who compare $V a R$ methodologies using descriptive statistics of the distributions of violations obtained via Monte Carlo simulations. Specifically, we simulate many trajectories of the return time series assuming different innovation distributions, and compute the number of violations ${ }^{4}$ using four different $V a R$ methodologies. For each simulated trajectory of the return series, we save the number of violations. At the end of the experiment, we will have a distribution of the number of violations for each $V a R$ methodology. Hence, we can compute descriptive statistics of the various distributions of violations and evaluate the quality of a $V a R$ methodology according to these statistics.

Our Monte Carlo simulations indicate that the robust model based on quantile regression dominates other models that requires distributional assumptions. In particular, the distribution of violations generated from non-robust models are right-skewed and presents excess kurtosis, meaning that these non-robust models have high probability to present trajectories with too many violations.

\footnotetext{
${ }^{3}$ This approach includes the weighted moving average method by J.P. Morgan's Riskmetrics and the hybrid method by Boudoukh, Richardson, and Whitelaw (1998).

${ }^{4}$ The number of violations is defined as the number of losses greater than $\operatorname{VaR}(\tau)$
} 
We illustrate our findings with an empirical application. We consider returns of the São Paulo stock exchange index, IBOVESPA, and show that the $V a R$ estimated by the quantile regression approach tends to predict $V a R \mathrm{~s}$ more accurately during periods of market stress.

The outline of this paper is as follows: In Section 2, we describe the general framework and present the competing models. We describe our Monte Carlo experiment in Section 3. An empirical illustration is provided in Section 4, and Section 5 concludes.

\section{The Competing Models}

Most of the $V a R$ methodologies are GARCH type models. Hence, they can be described using a GARCH framework (Giot and Laurent, 2004). GARCH models are designed to model the conditional heteroskedasticity in the time series of returns $y_{t}$, that is,

$$
\begin{aligned}
y_{t} & =\mu_{t}+\varepsilon_{t}, \\
\varepsilon_{t} & =\sigma_{t} z_{t}, \\
\mu_{t} & =c\left(\eta \mid I_{t-1}\right), \\
\sigma_{t} & =h\left(\eta \mid I_{t-1}\right),
\end{aligned}
$$

Where $c\left(\eta \mid I_{t-1}\right)$ and $h\left(\eta \mid I_{t-1}\right)$ are functions of the vector of parameters $\eta$ and of the information set $I_{t-1} ; z_{t}$ is an independent and identically distributed process, independent of $I_{t-1}$, with $E\left[z_{t}\right]=0$ and $\operatorname{Var}\left[z_{t}\right]=1 ; \mu_{t}$ is the conditional mean for $y_{t}$ and $\sigma_{t}^{2}$ is its conditional variance. The volatility model (2) encompass a family of methodologies used to predict $V a R$ s. We next describe some members of such family.

\subsection{RiskMetrics ${ }^{5}$}

RiskMetrics (J.P. Morgan, 1996) is the most simple analyzed methodology. However, it is still one of the most used model to compute $V a R$, and it is available for free by J.P. Morgan. In fact, RiskMetrics is a gaussian Integrated $\operatorname{GARCH}(1,1)$ model where the autoregressive parameter is set at a pre-specified value of 0.94 (for daily $V a R$, in the United States) and the decay parameter (it can be viewed as an exponential filter in volatility) is set at 0.06 , that is,

$$
\sigma_{t}^{2}=0.06 \varepsilon_{t-1}^{2}+0.94 \sigma_{t-1}^{2} .
$$

The conditional mean $\mu_{t}$ is estimated by OLS, running $y_{t}$ against its own lags ${ }^{6}$, and $z_{t} \sim N(0,1)$.

\footnotetext{
${ }^{5}$ RiskMetrics is a trademark by J.P. Morgan.

${ }^{6}$ The number of lags in the OLS regression can be choosen using Information Criteria. One can also add other conditioning variables.
} 


\subsection{Gaussian GARCH $(1,1)$}

In spite of using RiskMetrics, we could use the same $\operatorname{GARCH}(1,1)$ model but, instead of setting prespecified values of the parameters, we estimate them. In other words, we estimate the model

$$
\sigma_{t}^{2}=\omega+\alpha_{1} \varepsilon_{t-1}^{2}+\beta_{1} \sigma_{t-1}^{2},
$$

and $z_{t} \sim N(0,1)$.

This is the second model to be analyzed in our Monte Carlo experiment. The Gaussian (or Normal) GARCH(1,1) is expected to generate better forecasts than RiskMetrics, because the parameters are estimated rather than prespecified.

Observe that these two first models do not capture neither the asymmetric dynamics $^{7}$ nor all the leptokurtosis that is generally present in macroeconomics and financial time series, due to the fact that they assume normality for $z_{t}$. Indeed, in $V a R$ applications, the choice of a appropriate distribution for the innovation process $z_{t}$ is an important issue as it directly affects the quality of the estimation of the required quantiles. One way to weaken the assumption on the distribution of $z_{t}$ is to consider the Skewed Student-t APARCH model, which we describe next.

\subsection{Skewed Student-t APARCH(1,1)}

The APARCH (Ding, Granger and Engle, 1993) is an extension of the GARCH model that nests at least seven GARCH specifications. It can be described as

$$
\sigma_{t}^{\delta}=\omega+\alpha_{1}\left(\left|\varepsilon_{t-1}\right|-\gamma_{1} \varepsilon_{t-1}\right)^{\delta}+\beta_{1} \sigma_{t-1}^{\delta},
$$

where $\omega, \alpha_{1}, \gamma_{1}, \beta_{1}$ and $\delta(\delta>0)$ are parameters to be estimated. $\delta$ plays the role of a Box-Cox transformation of $\sigma_{t}$, while $\gamma_{1}\left(-1<\gamma_{1}<1\right)$ reflects the so-called leverage effect: the stylized fact that negative shocks impact volatility more than positive shocks.

Giot and Laurent (2003) and Giot (2003) use the above model considering a standardized version of the Skewed Student-t distribution - introduced by Fernández and Steel (1998) - for the $z_{t}$ process. They show that such standardized version provides more accurate $V a R$ forecasts than the GARCH model. This result is somehow expected, because the Skewed Student-t APARCH(1,1) nests the Gaussian GARCH $(1,1)^{8}$.

\footnotetext{
${ }^{7}$ Beaudry and Koop (1993) showed that positive shocks to US GDP are more persistent than negative shocks, indicating asymmetric business cycle dynamics. More recently, Nam et al. (2005) identified asymmetric dynamics for daily return on the S\&P 500 and used that to develop optimal technical trading strategies. In 1992, Brock, Lakonishok and LeBaron showed that two of the simplest and most popular trading rules - moving average and trading range break - consistently generate buy signals with higher returns than sell signals, and further, the returns following buy signals are less volatile than returns following sell signals.

${ }^{8}$ Indeed, the $\operatorname{GARCH}(1,1)$ is an $\operatorname{APARCH}(1,1)$ with $\delta=2$ and $\gamma_{1}=0$, and the Skewed Student-t distribution with the asymmetry coefficient $\xi=1$ (no asymmetry) converges to the Gaussian distribution when the degrees of freedom $\nu$ tends to the infinity.
} 
According to Lambert and Laurent (2001) and provided that the degrees of freedom $\nu>2$, the innovation process $z_{t}$ is said to follow a standardized Skewed Student-t distributed, i.e. $z_{t} \sim \operatorname{SKST}(0,1, \xi, \nu)$ if:

$$
f\left(z_{t} \mid \xi, \nu\right)=\left\{\begin{array}{c}
\frac{2}{\xi+\frac{1}{\xi}} s g\left[\xi\left(s z_{t}+m\right) \mid \nu\right], \text { if } z_{t}<-\frac{m}{s} \\
\frac{2}{\xi+\frac{1}{\xi}} s g\left[\frac{s z_{t}+m}{\xi} \mid \nu\right], \text { if } z_{t} \geq-\frac{m}{s}
\end{array}\right.
$$

where $g[\cdot \mid \nu]$ is a symmetric (unit variance) Student-t density and $\xi>0$ is the asymmetry coefficient. The parameters $m$ and $s^{2}$ are, respectively, the mean and the variance of the nonstandardized Skewed Student-t:

$$
m=\frac{\Gamma\left(\frac{\nu-1}{2}\right) \sqrt{\nu-2}}{\sqrt{\pi} \Gamma\left(\frac{\nu}{2}\right)}\left(\xi-\frac{1}{\xi}\right)
$$

and

$$
s^{2}=\left(\xi^{2}+\frac{1}{\xi^{2}}-1\right)-m^{2} .
$$

In short, $\xi$ models the asymmetry, while $\nu$ accounts for the tail thickness. See Lambert and Laurent (2001) for a discussion of the link between these two parameters and the skewness and the kurtosis.

\subsection{ARCH(q) Quantile}

Koenker and Zhao (1996) introduced the quantile regression model that allows for ARCH effect. The ARCH(q) Quantile methodology uses OLS estimator to estimate the conditional mean $\mu_{t}$, but this is the only similarity with the first three methodologies. The $\operatorname{ARCH}(q)$ Quantile does not assume any particular distribution to the process $z_{t}$. The model can be described as follows

$$
\begin{aligned}
& y_{t}=\mu_{t}+\varepsilon_{t}, \\
& \varepsilon_{t}=\left(\gamma_{0}+\gamma_{1}\left|\varepsilon_{t-1}\right|+\ldots+\gamma_{q}\left|\varepsilon_{t-q}\right|\right) z_{t} .
\end{aligned}
$$

Thus, the ARCH(q) Quantile specification assumes that the errors follow an $\operatorname{ARCH}(q)$ type $\operatorname{model}^{9}$, in which the fundamental innovation $z_{t}$ is drawn from an unknown distribution $F_{z}$.

In all the models presented in this paper, the $\operatorname{VaR}(\tau)$ is defined as the $\tau t h$ conditional quantile of the return, that is

$$
-\operatorname{VaR}_{t}(\tau)=\mu_{t}+Q_{\varepsilon}\left(\tau \mid I_{t-1}\right),
$$

where $Q_{\varepsilon}\left(\tau \mid I_{t-1}\right)$ is the conditional quantile function of $\varepsilon_{t}$.

Given a known distribution for the process $z_{t}$, the computation of (10) is straightforward. When the distribution of $z_{t}$ is unknown, we are led to the problem of quantile regression. The quantile regression method is an extension of the

\footnotetext{
${ }^{9}$ Observe both the similarities to and the differences from the classical ARCH specification introduced by Engle (1982).
} 
empirical quantile methods. While classical linear regression methods, based on minimization of the sum of squared residuals, enable one to estimate models for conditional mean functions, quantile regression methods offer a mechanism for estimating models for the conditional quantile functions, like the one appearing in (10). Thus, quantile regression is capable of providing a complete statistical analysis of the stochastic relationships among random variables.

Moreover, quantile regression method has the important property that it is robust to distributional assumptions. This property is inherited from the robustness property of the ordinary sample quantiles. Quantile estimation is only influenced by the local behavior of the conditional distribution of the response variable near the specified quantile. As a result, the estimated conditional quantile function is not sensitive to outlier observations. Such a property is specially attractive in financial applications since many financial data such as IBOVESPA returns are usually heavy-tailed and thus are not (conditional) normally distributed

\subsubsection{Quantile Regression}

As we stated above, the idea of quantile regression provides a natural way of estimating Value-at-Risk. Quantile regression was introduced by Koenker and Basset (1978) and has received a lot of attention in econometrics research in the past two decades. To introduce quantile regression, let $Y$ be a random variable with distribution function $F(y)$. The $\tau$-th quantile of $Y$ is defined by

$$
Q_{Y}(\tau)=\inf \{y \mid F(y) \geq \tau\} .
$$

Similarly, if we have a random sample $\left\{y_{1}, y_{2}, \ldots, y_{n}\right\}$ from the distribution $F$, the $\tau$-th sample quantile is:

$$
\hat{Q}_{y}(\tau)=\inf \{y \mid \hat{F}(y) \geq \tau\},
$$

where $\hat{F}$ is the empirical distribution function of the random sample. This sample quantile may be found by solving the minimization problem:

$$
\min _{b \in \mathbb{R}}\left[\sum_{t \in\left\{t: y_{t} \geq b\right\}} \tau\left|y_{t}-b\right|+\sum_{t \in\left\{t: y_{t}<b\right\}}(1-\tau)\left|y_{t}-b\right|\right] .
$$

Generalizing, if we consider the model:

$$
y_{t}=x_{t}^{\prime} b+\eta_{t}
$$

where $x_{t}$ is a $k \mathrm{x} 1$ vector of regressors including an intercept term. Then, conditional on the regressor $x_{t}$, the $\tau$-th quantile of $y$ :

$$
Q_{Y}\left(\tau \mid x_{t}\right)=\inf \left\{y \mid F\left(y \mid x_{t}\right) \geq \tau\right\},
$$

is a linear function of $x_{t}$ :

$$
b_{1}+x_{2 t}^{\prime} b_{2}+\ldots+x_{k t}^{\prime} b_{k}+F_{\varepsilon}^{-1}(\tau),
$$


where $F_{\varepsilon}(\cdot)$ is the cumulative distributional function of the residual. The $\tau$-th conditional quantile of $y$ can be estimated by an analogue of equation (13):

$$
\hat{Q}_{Y}\left(\tau \mid x_{t}\right)=x_{t}^{\prime} \hat{b}(\tau)
$$

where

$$
\hat{b}(\tau)=\arg \min _{b \in \mathbb{R}^{k}}\left[\sum_{t \in\left\{t: y_{t} \geq x_{t}^{\prime} b\right\}} \tau\left|y_{t}-x_{t}^{\prime} b\right|+\sum_{t \in\left\{t: y_{t}<x_{t}^{\prime} b\right\}}(1-\tau)\left|y_{t}-x_{t}^{\prime} b\right|\right]
$$

is called the quantile regression. As a special case, the least absolute deviation (LAD) estimator (or $l_{1}$ regression) is the median regression, i.e., the quantile regression for $\tau=0.5^{10}$.

\subsubsection{Estimating the ARCH Quantile $V a R$}

Given equation (9), we denote $\left(1,\left|\varepsilon_{t-1}\right|, \ldots,\left|\varepsilon_{t-q}\right|\right)^{\prime}$ as $X_{t}$ and the corresponding coefficient vector as $\gamma$. Then,

$$
Q_{\varepsilon}\left(\tau \mid I_{t-1}\right)=X_{t}^{\prime} \alpha(\tau),
$$

where

$$
\alpha(\tau)=\left(\gamma_{0} Q_{z}(\tau), \gamma_{1} Q_{z}(\tau), \ldots, \gamma_{q} Q_{z}(\tau)\right)^{\prime},
$$

and $Q_{z}(\tau)=F_{z}^{-1}(\tau)$ is the quantile function of $z$. By definition, $\operatorname{VaR}_{t}(\tau)$, the conditional Value-at-Risk at the $\tau$-th quantile is just

$$
-V a R_{t}(\tau)=\mu_{t}+X_{t}^{\prime} \alpha(\tau) .
$$

So we need to estimate $\widehat{\alpha}(\tau)^{11}$. It can be achieved by solving the problem:

$$
\widehat{\alpha}(\tau)=\arg \min _{\gamma \in \mathbb{R}^{q+1}}\left[\sum_{t \in\left\{t: u_{t} \geq Z_{t}^{\prime} \gamma\right\}} \tau\left|\varepsilon_{t}-X_{t}^{\prime} \gamma\right|+\sum_{t \in\left\{t: u_{t}<Z_{t}^{\prime} \gamma\right\}}(1-\tau)\left|\varepsilon_{t}-X_{t}^{\prime} \gamma\right|\right] .
$$

In practice, we can replace $\varepsilon_{t}$ by their OLS estimators $\widehat{\varepsilon}_{t}=y_{t}-\widehat{\mu}_{t}$. For example, if $\mu_{t}=\beta_{o}+\beta_{1} y_{t-1}$, then $\widehat{\varepsilon}_{t}=y_{t}-\widehat{\beta}_{o}-\widehat{\beta}_{1} y_{t-1}$, where $\widehat{\beta}_{o}$ and $\widehat{\beta}_{1}$ are estimated by OLS. Under mild regularity conditions, Koenker and Zhao (1996) show that $\widehat{\alpha}(\tau)$ estimated based on $\widehat{\varepsilon}_{t}$ is still a consistent estimator of $\alpha(\tau)$.

\section{Monte Carlo Simulations}

The objective of this section is to compare the four aforementioned $V a R$ methodologies. We perform Monte Carlo Simulations in which we generate 1000 time series with 1250 observations. We use a rolling window of 250 observations to

\footnotetext{
${ }^{10}$ For more on quantile regression, see Koenker (2005).

${ }^{11}$ Remember that $\widehat{\mu}_{t}$ is estimated by OLS.
} 
estimate the parameters of the four methodologies and forecast the $\operatorname{VaR}(1 \%)$ associated to the $251^{\text {st }}$ observation. The result is a 1-day-ahead $V a R$ time series, one for each methodology. At the end, we will have1001 forecast observations for each methodology. We decide for a 250 -observation window because it is the number of observations required to compute the multiplication factor $F_{t}$ in the Basle capital charge formula and because it is approximately 1 year, a reasonable time to be used by the banks, containing enough information for the parameters estimation, without losing too many observations. To find the violations, we need to compare the last 1000 observations of the generated series with the first 1000 observations of the $V a R$ forecasts. The choice for the $\operatorname{VaR}(1 \%)$ is due to regulatory purpose.

The DGPs used in this experiment are

$$
\begin{gathered}
y_{t}=0.5 y_{t-1}+\varepsilon_{t}, \\
\varepsilon_{t}=\sigma_{t} z_{t}, \\
\sigma_{t}^{2}=1+0.5 \varepsilon_{t-1}^{2}+\psi \sigma_{t-1}^{2},
\end{gathered}
$$

where $z_{t}$ are independent and identically distributed fundamental innovations, $z_{t} \sim$ i.i.d. There are five different innovation distributions, and we repeat the experiment with GARCH effect $(\psi=0.5)$. Therefore, there are ten DGPs that are described below.

Table 1. Data Generating Processes.

\begin{tabular}{|c|c|c|}
\hline DGP & Distribution of $z_{t}$ & $\psi$ \\
\hline 1 & $N(0,1)$ & 0 \\
\hline 2 & $t_{(3)}$ & 0 \\
\hline 3 & $\chi_{(1)}^{2}-\delta_{(1)}$ & 0 \\
\hline 4 & $\delta_{(2)}-G a m m a(2,1)$ & 0 \\
\hline 5 & $\chi_{(1)}^{2} I_{\left\{\nu_{t} \leq 0.2\right\}}+\left(\chi_{(1)}^{2}+\delta_{(-4)}\right) I_{\left\{0.2<\nu_{t} \leq 0.8\right\}}+\delta_{(-4)} I_{\left\{\nu_{t}>0.8\right\}}$ & 0 \\
\hline 6 & $N(0,1)$ & 0.5 \\
\hline 7 & $t_{(3)}$ & 0.5 \\
\hline 8 & $\chi_{(1)}^{2}-\delta_{(1)}$ & 0.5 \\
\hline 9 & $\delta_{(2)}-G a m m a(2,1)$ & 0.5 \\
\hline 10 & $\chi_{(1)}^{2} I_{\left\{\nu_{t} \leq 0.2\right\}}+\left(\chi_{(1)}^{2}+\delta_{(-4)}\right) I_{\left\{0.2<\nu_{t} \leq 0.8\right\}}+\delta_{(-4)} I_{\left\{\nu_{t}>0.8\right\}}$ & 0.5 \\
\hline
\end{tabular}

where $\delta_{\left(x_{0}\right)}$ is the Dirac's Delta density, which distribution $F_{\delta_{\left(x_{0}\right)}}(x)$ which is given by

$$
F_{\delta_{\left(x_{0}\right)}}(x)=\left\{\begin{array}{ll}
1, & \text { if } x \geq x_{0} \\
0, & \text { if } x<x_{0}
\end{array},\right.
$$

$I_{\{\cdot\}}$ is an indicator function that values 1 if the condition inside the braces is true and 0 otherwise, and $\nu_{t}$ is an independent and identically distributed standard uniform distribution, $\nu_{t} \sim U[0,1]$.

Therefore, $D G P_{1}$ corresponds to the standard gaussian one. In the $D G P_{2}$, $z_{t}$ are drawn from student-t distribution with 3 degrees of freedom (thus it has 
finite expectation and variance), so $z_{t}$ presents leptokurtosis. The distribution of $z_{t}$ in $D G P_{3}$ is no longer symmetric. The distribution of $z_{t}$ in $D G P_{4}$ and $D G P_{5}$ are nonstandard (with mass points) and they are considered to verify the robustness of $V a R$ methodologies against distributional misspecification. GARCH effect is introduced in $D G P_{6}$ to $D G P_{10}$.

\section{$3.1 \quad$ Results}

For each replication (with 1000 daily forecasts), the ideal number of violations of a $\operatorname{VaR}(1 \%)$ is 10 , but there are replications with more violations and there are replications with less violations. Hence, we shall analyze the distribution of the number of violations. Since there are 1000 replications, such a distribution of violations will have 1000 points (each point represents the number of violations that occurred in each trajectory). Recall that there are four $V a R$ methodologies labelled as $\operatorname{VaR} i, i=1,2,3,4$. Hence, $\operatorname{VaR} 1, \operatorname{VaR} 2, \operatorname{VaR} 3$, and $\operatorname{VaR}$ 4 correspond to the RiskMetrics, $\operatorname{GARCH}(1,1)$, APARCH(1,1), and $\operatorname{ARCH}(1)$ Quantile $V a R$ methodologies, respectively. We assess the performance of each $\operatorname{VaR}$ methodology under the ten aforementioned DGPs. Tables 2, 3 and 4 present location and scale parameter estimates of the various distributions of violations.

Table 2. Distributions of violations: estimated mean and bias.

\begin{tabular}{|c|c|c|c|c|}
\hline Methodology & VaR 1 & VaR 2 & VaR 3 & VaR 4 \\
\hline$D G P_{1}$ & 19.4 & 12.7 & 12.8 & 14.7 \\
\hline$D G P_{2}$ & 19.8 & 13.2 & 13.5 & 14.7 \\
\hline$D G P_{3}$ & 19.8 & 12.9 & 13.3 & 14.6 \\
\hline$D G P_{4}$ & 19.7 & 13.2 & 13.5 & 14.8 \\
\hline$D G P_{5}$ & 20.0 & 13.4 & 13.5 & 14.6 \\
\hline$D G P_{6}$ & 20.0 & 13.2 & 13.5 & 14.5 \\
\hline$D G P_{7}$ & 19.8 & 13.1 & 13.6 & 14.7 \\
\hline$D G P_{8}$ & 19.5 & 12.8 & 13.2 & 14.7 \\
\hline$D G P_{9}$ & 20.5 & 14.0 & 14.4 & 14.7 \\
\hline$D G P_{10}$ & 19.7 & 13.1 & 13.3 & 14.6 \\
\hline \multicolumn{5}{|c|}{ Bias } \\
\hline$D G P_{1}$ & 9.4 & 2.7 & 2.8 & 4.7 \\
\hline$D G P_{2}$ & 9.8 & 3.2 & 3.5 & 4.7 \\
\hline$D G P_{3}$ & 9.8 & 2.9 & 3.3 & 4.6 \\
\hline$D G P_{4}$ & 9.7 & 3.2 & 3.5 & 4.8 \\
\hline$D G P_{5}$ & 10.0 & 3.4 & 3.5 & 4.6 \\
\hline$D G P_{6}$ & 10.0 & 3.2 & 3.5 & 4.5 \\
\hline$D G P_{7}$ & 9.8 & 3.1 & 3.6 & 4.7 \\
\hline$D G P_{8}$ & 9.5 & 2.8 & 3.2 & 4.7 \\
\hline$D G P_{9}$ & 10.5 & 4.0 & 4.4 & 4.7 \\
\hline$D G P_{10}$ & 9.7 & 3.1 & 3.3 & 4.6 \\
\hline
\end{tabular}


On one hand, we notice in Table 2 that all four methodologies present positive estimated biases. The RiskMetrics methodology is the most biased and the Gaussian GARCH$(1,1)$ has the least bias. The robust $\mathrm{ARCH}(1)$ Quantile method exhibits a very stable estimated bias across different innovation distributions. On the other hand, Table 3 shows that the variance is much higher (one order of magnitude higher) in the first three methodologies than in the $\operatorname{ARCH}(1)$ Quantile.

We compute in Table 3 the range of the distribution of the number of violations, i.e., the difference between the maximum and the minimum number of violations. We notice that the fourth methodology has the lowest range. Indeed, as shown in Table 4, its maximum value never exceeds 27 violations, which can be considered a good performance in a $V a R(1 \%)$. The non-robust methodologies have maximum number of violations at least three times as large as the ARCH(1) Quantile method. This excess dispersion invalidates the first three $V a R$ methodologies, since they jeopardize the bank or institution that use them to compute $V a R$ measures. It is not acceptable for a measure of risk to be too risky, in the sense that its probability of having trajectories with too many violations is too high. A bank may go belly-up if this trajectory is the true (realized) one.

Table 3. Distributions of violations: estimated variance and range.

\begin{tabular}{|c|c|c|c|c|}
\hline Methodology & $V a R 1$ & $V a R 2$ & $V a R 3$ & $V a R 4$ \\
\hline \multicolumn{5}{|c|}{ Variance } \\
\hline$D G P_{1}$ & 62.1 & 88.1 & 80.5 & 7.4 \\
\hline$D G P_{2}$ & 72.0 & 105.4 & 102.2 & 7.5 \\
\hline$D G P_{3}$ & 72.5 & 103.3 & 100.1 & 7.5 \\
\hline$D G P_{4}$ & 66.6 & 102.7 & 93.6 & 7.3 \\
\hline$D G P_{5}$ & 69.0 & 102.1 & 98.7 & 8.1 \\
\hline$D G P_{6}$ & 68.5 & 103.9 & 97.1 & 6.8 \\
\hline$D G P_{7}$ & 74.7 & 104.6 & 104.6 & 8.1 \\
\hline$D G P_{8}$ & 59.9 & 89.2 & 87.4 & 7.5 \\
\hline$D G P_{9}$ & 89.2 & 133.2 & 127.2 & 7.7 \\
\hline$D G P_{10}$ & 61.5 & 100.5 & 90.4 & 6.7 \\
\hline \multicolumn{5}{|c|}{ Range $(\mathrm{Max}-\mathrm{Min})$} \\
\hline$D G P_{1}$ & 70 & 81 & 72 & 19 \\
\hline$D G P_{2}$ & 68 & 65 & 68 & 18 \\
\hline$D G P_{3}$ & 72 & 76 & 76 & 19 \\
\hline$D G P_{4}$ & 62 & 65 & 63 & 20 \\
\hline$D G P_{5}$ & 69 & 74 & 64 & 20 \\
\hline$D G P_{6}$ & 61 & 62 & 65 & 16 \\
\hline$D G P_{7}$ & 61 & 67 & 73 & 18 \\
\hline$D G P_{8}$ & 70 & 71 & 67 & 18 \\
\hline$D G P_{9}$ & 63 & 70 & 68 & 17 \\
\hline$D G P_{10}$ & 62 & 74 & 70 & 17 \\
\hline
\end{tabular}


On the other hand, the Gaussian $\operatorname{GARCH}(1,1)$ and the Skewed Student-t $\operatorname{APARCH}(1,1)$ present some trajectories with very few violations. In fact, the former has trajectories with no violations at all.

Table 4. Distributions of violations: estimated minimum and maximum.

\begin{tabular}{|c|c|c|c|c|}
\hline Methodology & VaR 1 & VaR 2 & VaR 3 & VaR 4 \\
\hline \multicolumn{5}{|c|}{ Minimum Value (Min) } \\
\hline$D G P_{1}$ & 6 & 2 & 3 & 7 \\
\hline$D G P_{2}$ & 7 & 3 & 3 & 7 \\
\hline$D G P_{3}$ & 8 & 3 & 2 & 6 \\
\hline$D G P_{4}$ & 7 & 1 & 2 & 7 \\
\hline$D G P_{5}$ & 6 & 3 & 2 & 3 \\
\hline$D G P_{6}$ & 7 & 1 & 2 & 7 \\
\hline$D G P_{7}$ & 7 & 3 & 3 & 7 \\
\hline$D G P_{8}$ & 6 & 0 & 2 & 5 \\
\hline$D G P_{9}$ & 8 & 2 & 3 & 7 \\
\hline$D G P_{10}$ & 6 & 3 & 1 & 7 \\
\hline & $M a x i m u m$ & Value $(\mathrm{Max})$ & \\
\hline$D G P_{1}$ & 76 & 83 & 75 & 26 \\
\hline$D G P_{2}$ & 75 & 68 & 71 & 25 \\
\hline$D G P_{3}$ & 80 & 79 & 78 & 25 \\
\hline$D G P_{4}$ & 69 & 66 & 65 & 27 \\
\hline$D G P_{5}$ & 75 & 77 & 66 & 23 \\
\hline$D G P_{6}$ & 68 & 63 & 67 & 23 \\
\hline$D G P_{7}$ & 68 & 70 & 76 & 25 \\
\hline$D G P_{8}$ & 76 & 71 & 69 & 23 \\
\hline$D G P_{9}$ & 71 & 72 & 71 & 24 \\
\hline$D G P_{10}$ & 68 & 77 & 71 & 24 \\
\hline
\end{tabular}

The $\operatorname{ARCH}(1)$ Quantile VaR exhibits the second greatest bias, but displays the lowest variance and range. To assess the trade-off between bias and variance, we adopt the Mean Squared Error (MSE), abiding by the formula (see Engle and Manganelli, 2001)

$$
\operatorname{MSE}(\hat{X}):=\frac{1}{1000} \sum_{i=1}^{1000}\left(X_{i}-10\right)^{2},
$$

where $X_{i}$ is the number of violation in the $i$-th replication, 1000 is the total number of replications and 10 is the ideal number of violations, for a $\operatorname{VaR}(1 \%)$, at each replication. It can be shown that the $M S E(\hat{X})=\operatorname{Var}(\hat{X})+\operatorname{Bias}(\hat{X})^{2}$, where $\operatorname{Bias}(\hat{X})=\bar{X}-10$ and $\bar{X}=\frac{1}{1000} \sum_{i=1}^{1000} X_{i}$. The bias and the MSE are show in Table 5.

Notice that, even considering the bias, the ARCH(1) Quantile VaR methodology has, by far, the lowest MSE. We can see that the estimated MSE is pretty stable across the different DGPs for the robust ARCH(1) method. 
Table 5. Distributions of violations: estimated Mean Squared Error.

\begin{tabular}{|c|c|c|c|c|}
\hline Methodology & VaR 1 & VaR 2 & VaR 3 & VaR 4 \\
\hline \multicolumn{5}{|c|}{ Mean Squared Error } \\
\hline$D G P_{1}$ & 150.7 & 95.3 & 88.1 & 29.6 \\
\hline$D G P_{2}$ & 168.8 & 115.4 & 114.6 & 29.5 \\
\hline$D G P_{3}$ & 168.0 & 110.9 & 110.9 & 29.0 \\
\hline$D G P_{4}$ & 160.9 & 112.7 & 106.1 & 30.3 \\
\hline$D G P_{5}$ & 169.3 & 113.5 & 111.0 & 29.2 \\
\hline$D G P_{6}$ & 167.9 & 113.7 & 109.0 & 27.0 \\
\hline$D G P_{7}$ & 170.3 & 114.1 & 117.3 & 29.8 \\
\hline$D G P_{8}$ & 151.0 & 97.1 & 97.6 & 29.2 \\
\hline$D G P_{9}$ & 199.8 & 149.0 & 146.7 & 29.8 \\
\hline$D G P_{10}$ & 155.0 & 109.8 & 101.3 & 28.0 \\
\hline
\end{tabular}

We show in Table 6 estimates of skewness and excess kurtosis of the distributions of number of violations. We observe that the non-robust $V a R$ methodologies yield distributions of violations that are skewed to the right and possess excess kurtosis. Again, the robust ARCH(1) Quantile method gives rise to an well-behaved distribution of violations, with almost none skewness nor excess kurtosis.

Table 6. Distributions of violations: estimated skewness and excess kurtosis.

\begin{tabular}{|c|c|c|c|c|}
\hline Methodology & $V a R 1$ & $V a R 2$ & $V a R 3$ & $V a R 4$ \\
\hline \multicolumn{5}{|c|}{ Skewness } \\
\hline$D G P_{1}$ & 2.8 & 3.2 & 3.3 & 0.3 \\
\hline$D G P_{2}$ & 2.6 & 2.8 & 3.0 & 0.3 \\
\hline$D G P_{3}$ & 2.7 & 3.0 & 3.1 & 0.3 \\
\hline$D G P_{4}$ & 2.6 & 2.8 & 2.8 & 0.3 \\
\hline$D G P_{5}$ & 2.6 & 2.8 & 2.7 & 0.1 \\
\hline$D G P_{6}$ & 2.6 & 2.8 & 2.8 & 0.2 \\
\hline$D G P_{7}$ & 2.7 & 2.9 & 2.9 & 0.2 \\
\hline$D G P_{8}$ & 2.6 & 2.9 & 2.9 & 0.2 \\
\hline$D G P_{9}$ & 2.4 & 2.6 & 2.6 & 0.2 \\
\hline$D G P_{10}$ & 2.6 & 2.9 & 2.9 & 0.1 \\
\hline \multicolumn{5}{|c|}{ Excess } \\
\hline$D G P_{1}$ & 10.1 & 11.6 & 11.9 & 0.2 \\
\hline$D G P_{2}$ & 8.2 & 7.8 & 9.2 & 0.1 \\
\hline$D G P_{3}$ & 8.5 & 8.9 & 10.4 & 0.2 \\
\hline$D G P_{4}$ & 7.8 & 7.5 & 7.7 & 0.6 \\
\hline$D G P_{5}$ & 8.3 & 7.8 & 7.2 & 0.1 \\
\hline$D G P_{6}$ & 8.0 & 7.5 & 7.8 & 0.0 \\
\hline$D G P_{7}$ & 8.5 & 8.2 & 8.8 & 0.1 \\
\hline$D G P_{8}$ & 8.8 & 8.7 & 8.9 & 0.0 \\
\hline$D G P_{9}$ & 6.1 & 6.2 & 6.4 & 0.0 \\
\hline$D G P_{10}$ & 8.5 & 8.9 & 9.1 & 0.2 \\
\hline
\end{tabular}


For completeness, we present the histograms of the number of violations for the four methodologies under the five DGPs with GARCH effect in Figures 1 to 5. It is clear that the non-robust methods present some trajectories with too many violations. Moreover, the estimated distribution of the number of violations is more concentrated in the fourth methodology, under all DGPs.

In sum, our Monte Carlo experiment suggests that the robust method dominates the other methods, since the former yields a distribution of number of violations that present very low MSE, almost none skewness and excess kurtosis. More importantly, these nice properties are preserved over a wide range of innovation distributions, with or without GARCH effect. This result is expected because the robust method does not depend on distributional assumption.

Figure 1. Histograms of the number of violations under DGP 6.

VaR 1

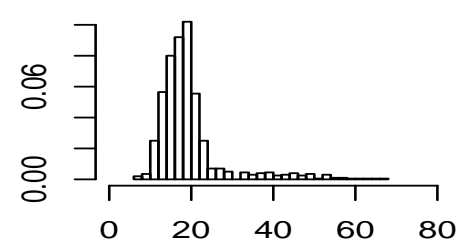

VaR 3

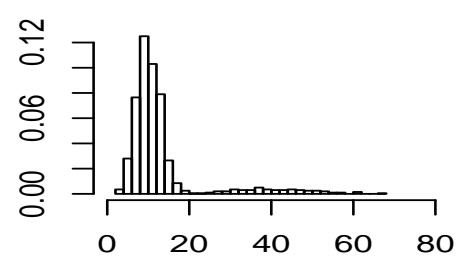

VaR 2

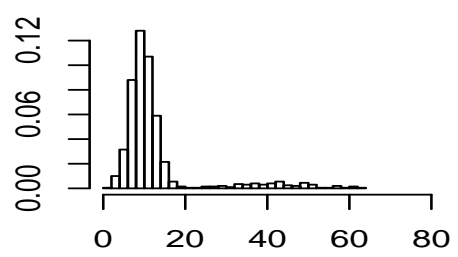

VaR 4

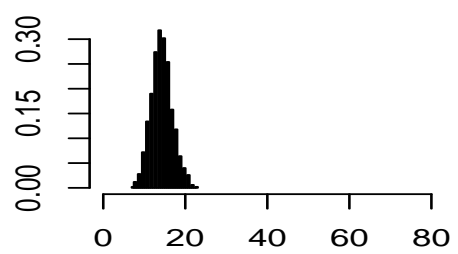


Figure 2. Histograms of the number of violations under DGP 7.

VaR 1

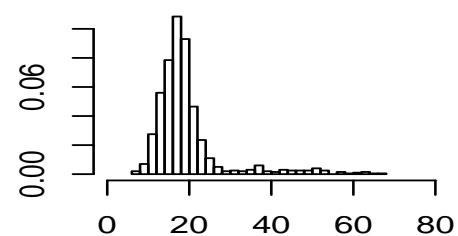

VaR 3

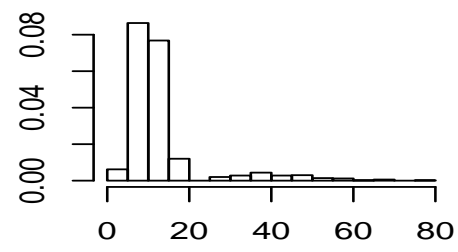

VaR 2

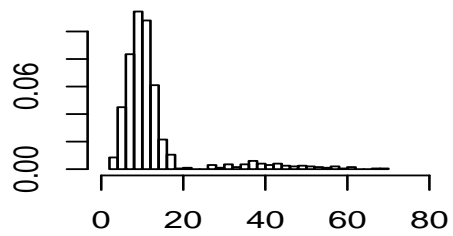

VaR 4

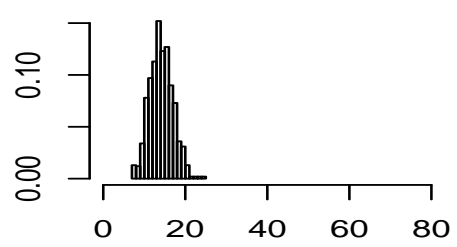

Figure 3. Histograms of the number of violations under DGP 8.

VaR 1

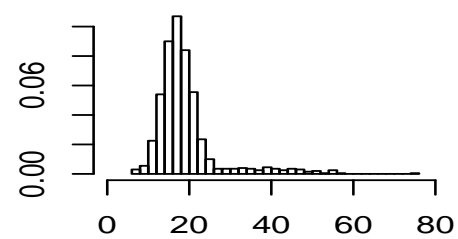

VaR 3

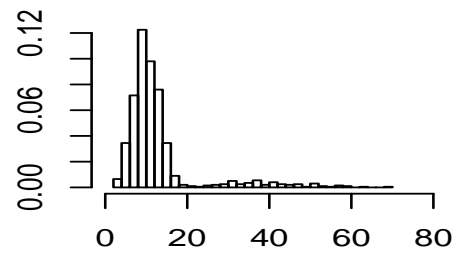

VaR 2

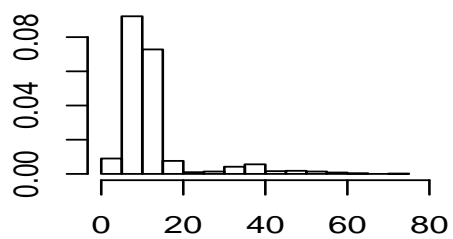

VaR 4

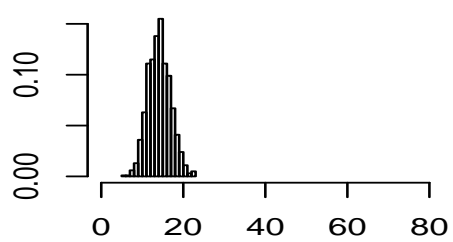


Figure 4. Histograms of the number of violations under DGP 9.

VaR 1

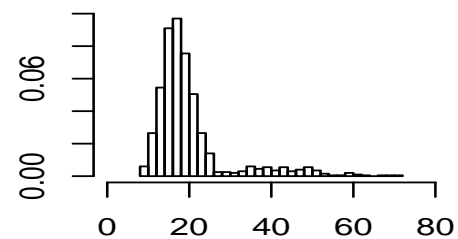

VaR 3

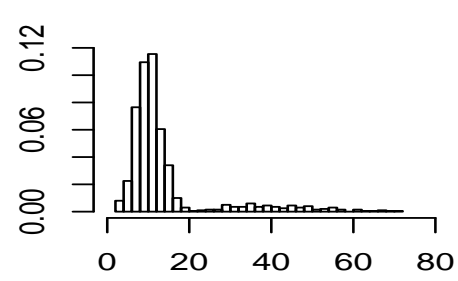

VaR 2

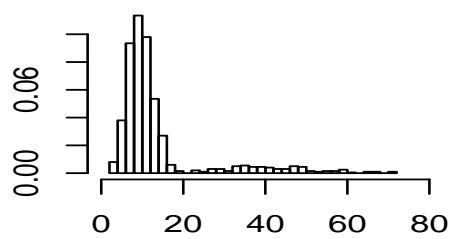

VaR 4

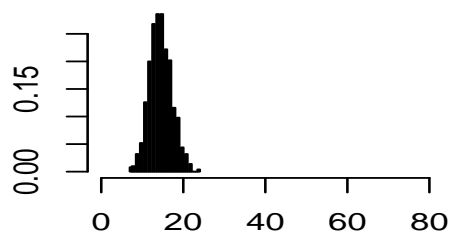

Figure 5. Histograms of the number of violations under DGP 10.

VaR 1

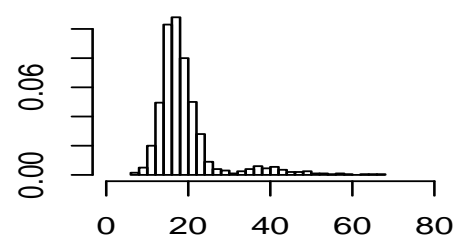

VaR 3

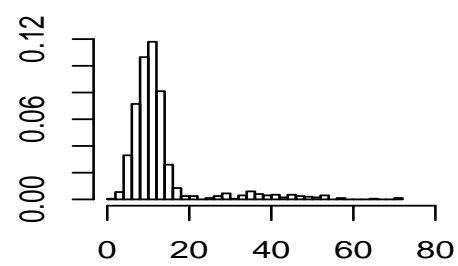

VaR 2

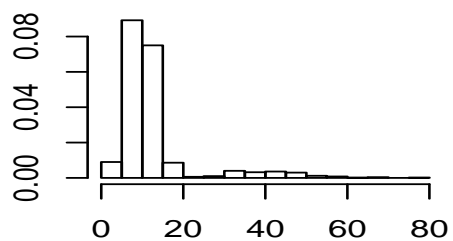

VaR 4

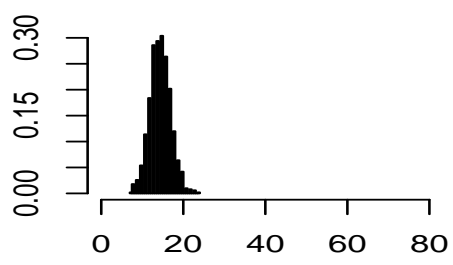




\subsection{Backtest}

The Unconditional Coverage backtest was proposed by Kupiec (1995). Under the null hypothesis that $P\left[r_{t}<-V a R_{t}(\tau) \mid I_{t-1}\right]=\tau, \forall t$, i.e., that the probability of occurrence of a violation is indeed $\tau$, the number of violations, $X$, in a given time span, $T$, follows a binomial distribution: $X \sim \operatorname{Binomial}(T, \tau)$. Define $\hat{\tau}:=\frac{X}{T}$. Then, the likelihood ratio test statistic ${ }^{12}$ is

$$
L R_{u c}=2 \ln \left(\frac{\hat{\tau}^{X}(1-\hat{\tau})^{T-X}}{\tau^{X}(1-\tau)^{T-X}}\right) .
$$

Under the null hypothesis that $\tau=\hat{\tau}, L R_{u c} \sim \chi_{(1)}^{2}$.

Table 7 shows the probability of rejection, at $1 \%$ level of significance, of the null hypothesis of correct unconditional coverage, i.e., the hypothesis that the probability of the occurrence of a violation is indeed $1 \%$. All the four methodologies present an oversized test. However, the RiskMetric model is rejected in one third of the trajectories, approximately, while the ARCH Quantile VaR is rejected in $4 \%$ or $5 \%$ of the replications.

Table 7. Empirical size for the Unconditional Coverage test.

\begin{tabular}{|c|c|c|c|c|}
\hline Methodology & $V a R 1$ & $V a R 2$ & $V a R 3$ & $V a R 4$ \\
\hline \multicolumn{5}{|c|}{ Size at 1\% significance level } \\
\hline$D G P_{1}$ & 0.342 & 0.082 & 0.080 & 0.050 \\
\hline$D G P_{2}$ & 0.361 & 0.100 & 0.097 & 0.045 \\
\hline$D G P_{3}$ & 0.346 & 0.094 & 0.093 & 0.042 \\
\hline$D G P_{4}$ & 0.339 & 0.100 & 0.098 & 0.042 \\
\hline$D G P_{5}$ & 0.369 & 0.106 & 0.108 & 0.054 \\
\hline$D G P_{6}$ & 0.370 & 0.100 & 0.098 & 0.037 \\
\hline$D G P_{7}$ & 0.349 & 0.101 & 0.101 & 0.052 \\
\hline$D G P_{8}$ & 0.345 & 0.100 & 0.098 & 0.043 \\
\hline$D G P_{9}$ & 0.359 & 0.126 & 0.126 & 0.047 \\
\hline$D G P_{10}$ & 0.327 & 0.099 & 0.097 & 0.034 \\
\hline
\end{tabular}

\section{An Empirical Illustration}

\subsection{The Data}

We perform an empirical exercise using daily returns, in US dollars, of the Brazilian São Paulo Stock Exchange Index (IBOVESPA) from 08/07/1996 to $24 / 03 / 2000$, summing up 920 observations. We choose this sample because we want to check the performance of each $V a R$ methodology during periods of market turmoil. Indeed, the above sample period covers the Korean Crisis in 1997, the Russian crisis in 1999, and the blast of the technology-stock market bubble in 2000. Figure 6 displays the behavior of the IBOVESPA return over the above sample period.

\footnotetext{
${ }^{12}$ This is the uniformly most powerful (UMP) test for a given $T$.
} 
Figure 6. IBOVESPA return time series.

\section{IBOVESPA}

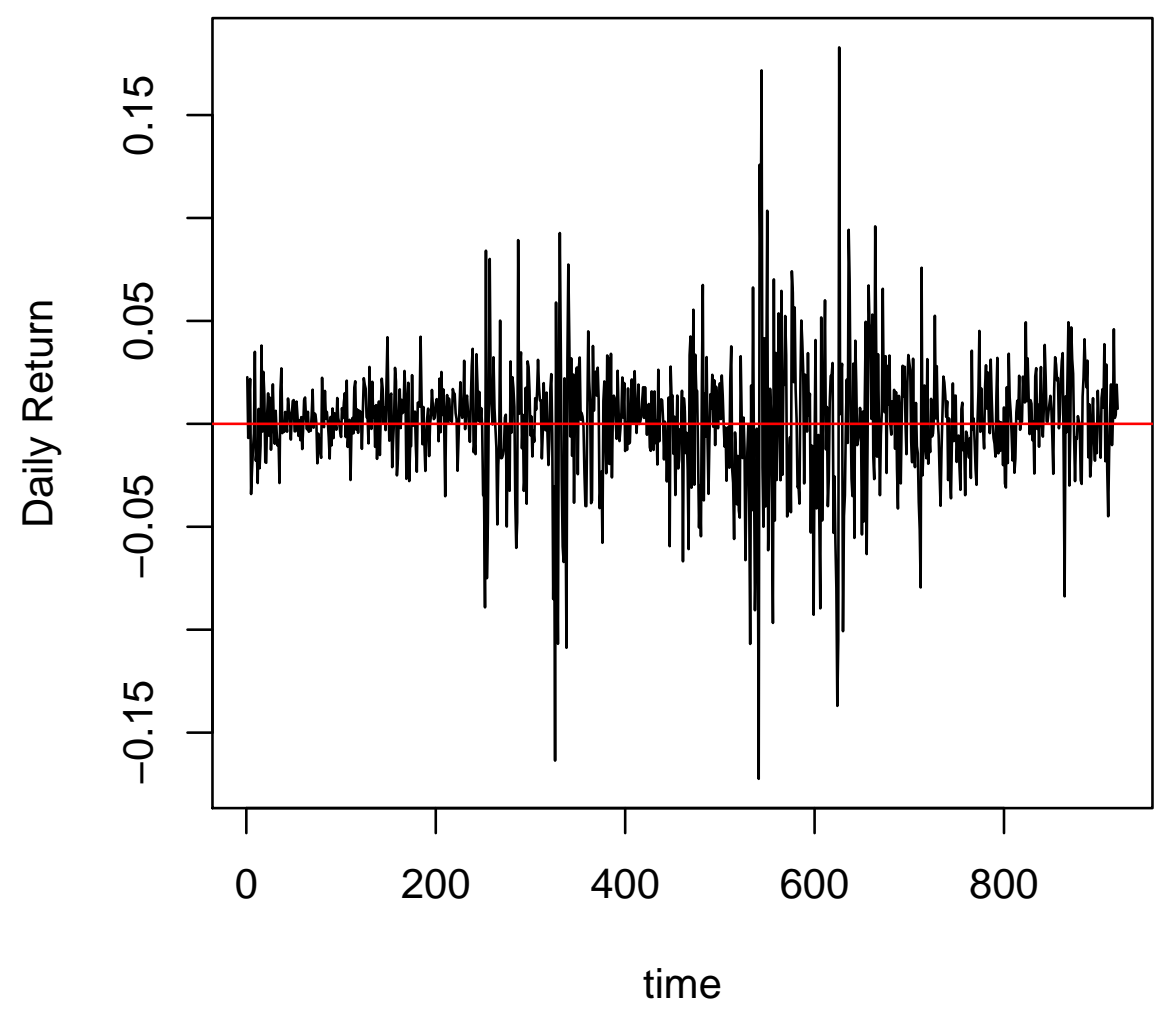

It is well known that GARCH volatility models tend to predict implausible high $V a R$ during periods of market turmoil. This happens because GARCH models treat both large positive and large negative return shocks as indicators of high volatility, which only large negative return shocks indicate higher Value-atRisk. In other words, volatility and $V a R$ are not the same thing, and this is not taken into account by the non-robust GARCH volatility models ${ }^{13}$. In contrast, the robust ARCH Quantile, while predicting higher volatility in the ARCH component, assigns a much larger weight to a big negative return shock than to a big positive return shock and, thus, we expect that the resulting estimated $V a R$ s are closer to reality during periods of market turmoil (see similar argument in $\mathrm{Wu}$ and Xiao, 2002).

\footnotetext{
${ }^{13}$ It is true, however, that the APARCH model assigns different weights to negative and positive shocks which helps avoiding estimation of high $V a R$ s during periods of market stress.
} 
We next examine the distribution of the Ibovespa return. It was argued in this paper that, unlike the non-robust methods, the ARCH Quantile method has no need to specify the distribution of the innovation process, $z_{t}$. The importance of this robustness aspect is revealed by the Quantile-Quantile plots (QQ plot). Recall that the QQ plot graphs the quantiles of the observed variable (IBOVESPA return) against the quantiles of a specified distribution. Hence, if the returns are distributed according to that specified distribution, then the points in the QQ-plots should lie alongside a straight line. The next two Figures show the QQ plots against all the five innovation distributions used in our Monte Carlo experiment.

Figure 7. Q-Q Plot of the IBOVESPA return versus the Normal distribution.

\section{Q-Q Plot: Standard Gaussian}

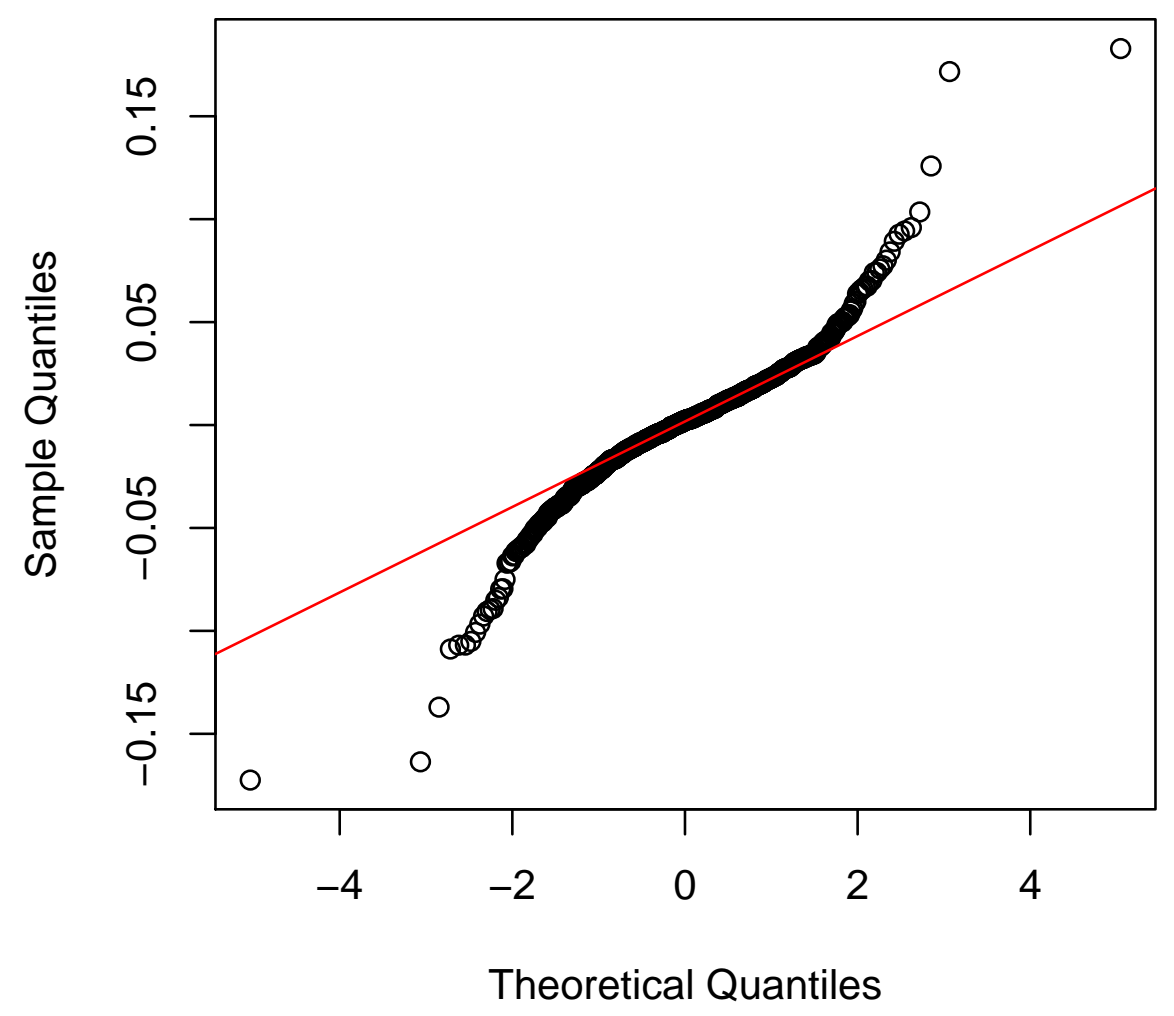

Figure 7 indicates that it is primarily large negative and positive shocks that are driving the departure from normality. In other words, the tail behavior of the distribution of the IBOVESPA return are far different from the tail behavior of 
a Gaussian distribution. Figure 8 exhibits the QQ plots against the 4 remaining distributions. It seems that the student-t distribution with 3 degrees of freedom approximates the data distribution reasonably well, but there still be extreme positive and negative observations that lie off the straight line suggesting that the student-t distribution with 3 degrees of freedom does not fit the tail of the data distribution pretty well, what is particularly bad for risk measures. Figures 8 also shows that the data distribution departures from the other 3 distributions considered in our Monte Carlo experiment, but they fit the data distribution even worse than the previous two distributions.

Thus, given this uncertainty about the specification of the innovation distribution, how could we go about computing Value-at-Risk correctly? A natural answer to it is to use a method robust against distribution misspecification, such as the method based on the ARCH Quantile model.

Figure 8. Q-Q Plots of the IBOVESPA return versus the other distributions.
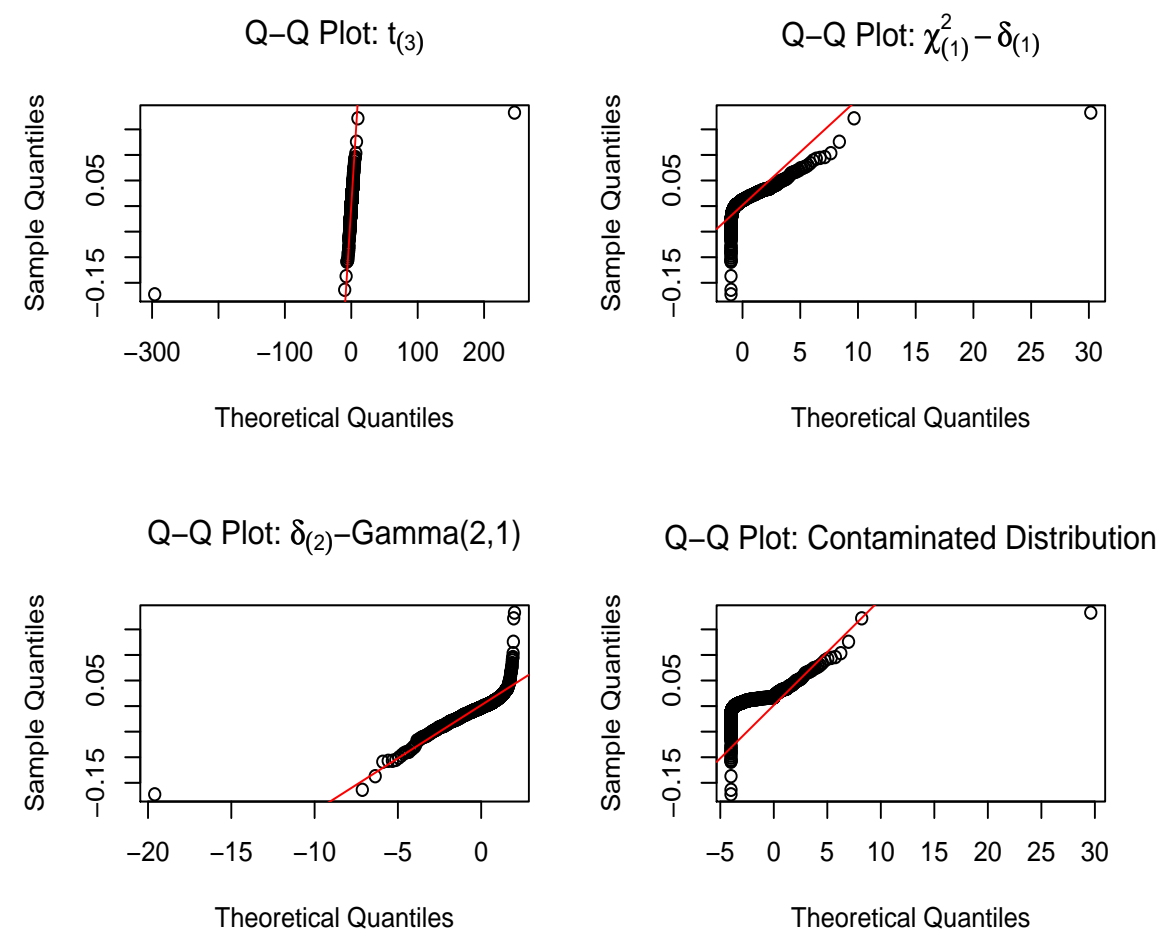

\subsection{The Estimated VaRs}

Notice that there is no $V a R$ forecast for the first 250 observations, due to the first temporal window. Hence, there are 670 1-day-ahead forecast observations for each $\operatorname{VaR}(1 \%)$ methodology, ranging from $11 / 07 / 1997$ to $24 / 03 / 2000$. Since it is a $1 \%$ Value-at-Risk, we expect about 7 violations. Before we move to 
the results of our empirical illustration, it is important to mention that the comparison of different $V a R$ methodologies depends on the specification of $\mu_{t}$ (the conditional mean) and the specifications of the conditional volatility. In the empirical example that follows, we consider $\mu_{t}=\beta_{o}+\beta_{1} y_{t-1}{ }^{14}$. As for the number of lags appearing in the definition of $\varepsilon_{t}$ in equation (9), we follow $\mathrm{Wu}$ and Xiao (2002) and use a Wald test to determine the optimal lag choice ${ }^{15}$. As for the order of the GARCH and APARCH models, we follow Enders (2003, pp 136) and use adjusted information criteria.

Table 8 shows the results of the Unconditional Coverage Test.

Table 8. Unconditional Coverage Test.

\begin{tabular}{|c|c|c|c|c|}
\hline Methodology & $V a R 1$ & $V a R 2$ & $V a R 3$ & $V a R 4$ \\
\hline Number of Violations & 14 & 12 & 13 & 11 \\
\hline Test Statistic $L R_{u c}$ & 6.115232 & 3.429641 & 4.693915 & 2.335267 \\
\hline P-Value & 0.013402 & 0.064036 & 0.030270 & 0.126473 \\
\hline
\end{tabular}

Note that the number of violations in the RiskMetrics methodology is the greatest, while the ARCH(1) Quantile presents the greatest p-value in the Unconditional Coverage test, that is to say, we do not reject, even at a $10 \%$ significance level, the null hypothesis that the conditional probability of occurrence of a violation in this $1 \%$ Value-at-Risk estimated time series is indeed $1 \%$. The $\operatorname{GARCH}(1,1)$ does not present a bad result, since we do not reject, at least at $5 \%$ significance level, the null hypothesis of correct unconditional coverage.

\section{Conclusion}

We perform a Monte Carlo experimet to compare four different Value-at-Risk methodologies, RiskMetrics, Gaussian GARCH(1,1), Generalized Student-t APARCH(1,1), and $\operatorname{ARCH}(1)$ Quantile, under ten different data generating processes. The $\mathrm{ARCH}(1)$ Quantile methodology does not assume any distribution for the returns, and this robustness is shown to avoid trajectories with too many violations. The number of violations tends to be higher in the non-robust methodologies.

We also perform an empirical exercise applying the four Value-at-Risk methodologies to daily return of the IBOVESPA (measured in dollar values) in a period of market turmoil (1996-2000), when happens the Korean crisis, the Russian crisis and the blast of the technology-stock market bubble. We show again that the $\mathrm{ARCH}(1)$ Quantile methodology dominates the non-robust methodologies, in the sense that it presents the least number of violations.

\footnotetext{
${ }^{14}$ First-order serial correlation in returns is not necessarily at odds with the efficient market hypothesis. See Campbell et al. (1997) for a detailed discussion.

${ }^{15} \mathrm{As}$ all the other $\mathrm{R}$ and $\mathrm{Ox}$ codes used in this paper, this test is available on www.fgv.br/aluno/bneri.
} 


\section{A Appendix: Computational Details}

We use $\mathrm{R}$ and $\mathrm{Ox}$ to conduct this experiment. The former is an open source computer-programming language. Hence, it (and its source codes) can be freely downloaded from the Internet ${ }^{16}$. This availability keeps $\mathrm{R}$ always updated with the most recent techniques in Statistics, Econometrics and Computer Science. Ox can also be downloaded from internet for research purpose $\mathrm{e}^{17}$.

The time series are generated in $\mathrm{R}$ because its default ${ }^{18}$ Random Number Generator (RNG) is the Mersenne-Twister (see Matsumoto and Nishimura, 1998), an impressive RNG with period $2^{19937}-1$ and equidistribution in 623 consecutive dimensions (over the whole period).

This Monte Carlo experiment is extremely computational intensive. For each observation in the $V a R$ forecast, there are three likelihood maximizations - RiskMetrics, Gaussian GARCH(1,1) and Skewed Student-t APARCH(1,1) with 250 observations (the window length) each. The third maximization occurs in a 7 -dimensional hyperplane within a 8 -dimensional space $(5$ parameters for the $\operatorname{APARCH}(1,1)$ specification and 2 parameters for the Skewed Student-t distribution). The $\mathrm{R}$ is supposed to take several months to conclude all the Monte Carlo, even in our server with 4 Intel Pentium IV Xeon at $2.8 \mathrm{GHz}$, a 4 GB RAM and a 100 GB SCSI Hard Disk running Linux Debian as Operating System. $\mathrm{R}$ is not so fast since it is an interpreted language: the interpreter executes the code line by line, so the user can enter a single line and see the results, which makes it more interactive and user-friendly. Ox is one order of magnitude faster than $\mathrm{R}$ since it is a compiled language: the compiler analyses the code as a whole, really optimizing it before executing it, which makes it much faster in large computations.

However, the ARCH(1) Quantile VaR must be estimated in R because the quantreg package for $\mathrm{R}$, version 3.82, May 15, 2005, developed mostly by Roger Koenker himself, is very complete and operational ${ }^{19}$. Thus, we proceed as follows: $\mathrm{R}$ generates the time series, then it calls $\mathrm{Ox}$ to estimate the first three $V a R$ methodologies ${ }^{20}$. Next, Ox returns these $V a R$ forecasts to R, that estimates the ARCH(1) Quantile VaR, computes the descriptive statistics, and saves the results in the Hard Disk. $\mathrm{R}$ then generates another time series and the next replication begins. Using this hybrid solution ( $\mathrm{Ox}$ and $\mathrm{R}$ ), all the Monte Carlo experiment takes a couple of month. Every written code, for both R and Ox, used in this paper are available on www.fgv.br/alluno/bneri.

\footnotetext{
16 www.r-project.org

17 www.doornik.com

${ }^{18}$ Alternatively, the user can select one of the eight RNGs available, or to supply another one.

${ }^{19} \mathrm{Ox}$ has also a code called $r q$ to, at least, estimate quantile regression, but it is quite incomplete. It was written by a Roger Koenker's student, Daniel Morillo, but it has been abandoned in its version 1.0, August 1999.

${ }^{20}$ Our Ox code uses some function from the package G@RCH 4.0, by Laurent and Peters (see Laurent and Peters, 2005), for Ox.
} 


\section{References}

[1] Basle Committee on Banking Supervision, 1996. Amendment to the Capital Accord to Incorporate Market Risks.

[2] Beaudry, P. and G. Koop, 1993. Do Recessions Permanently Change Output? Journal of Monetary Economics 31, 149-163.

[3] Box, G.E.P. and M.E. Muller, 1958. A Note on the Generation of Normal Random Deviates. Annals of Mathematical Statistics 29, 610-611.

[4] Boudoukh, J., M. Richardson, and R.F. Whitelaw, 1998. The Best of Both Worlds. Risk, 11, 64-67.

[5] Brazilian Central Bank, (March) 2001. Resolution $\mathrm{N}^{0} 2.829$.

[6] Brock, William, Josef Lakonishok and Blake LeBaron, December 1992. Simple Technical Trading Rules and the Stochastic Properties of Stock Returns. The Journal of Finance Vol. XLVII, N ${ }^{0} 5$.

[7] Campbell, John Y., Andrew W. Lo and A. Craig MacKinlay, 1997. The Econometrics of Finantial Markets. Princeton University Press.

[8] Chernozhukov, Victor and Umantsev, Len, 2001. Conditional Value-atRisk: Aspects of Modelling and Estimation. Empirical Economics 26 (1), 271-292.

[9] Ding, Zhuanxin, Clive W. J. Granger and Robert F. Engle, 1993. A Long Memory Property of Stock Market Returns and a New Model. Journal of Empirical Finance 1, 83-106.

[10] Doornik, J.A., 2002. Object-Oriented Matrix Programming Using Ox. Timberlake Consultants Press and Oxford, 3rd ed., London.

[11] Enders, W., 2003. Aplied Econometric Time Series, 2nd edition. Wiley Series in Probability and Statistics.

[12] Engle, Robert F. and Simone Manganelli, 2001. Value-at-Risk Models in Finance. Working Paper 75, Working Paper Series, European Central Bank.

[13] Engle, Robert F. and Simone Manganelli, 1999. CAViaR: Conditional Autoregressive Value at Risk by Regression Quantiles. University of California, San Diego, Working Paper.

[14] Engle, Robert F., 1982. Autoregressive Conditional Heteroskedasticity With Estimates of the Variance of U.K. Inflation. Econometrica 50, 9871008.

[15] Fernández, C. and M. Steel, 1998. On Bayesian Modelling of Fat Tails and Skeweness. Journal of The American Statistical Association 93, 359-371. 
[16] Giot, Pierre, 2003. The information content of implied volatility in agricultural commodity markets. Journal of Futures Markets 23, 441-454.

[17] Giot, Pierre and Sébastien Laurent, 2003. Value-at-Risk for long and short positions. Journal of Applied Econometrics 18, 641-664.

[18] Giot, Pierre and Sébastien Laurent, 2004. Modelling daily Value-at-Risk using realized volatility and ARCH type models. Journal of Empirical Finance 11, 379-398.

[19] J. P. Morgan, December 17, 1996. RiskMetrics. J. P. Technical Document, Fourth Edition.

[20] Koenker, Roger, 2005. Quantile Regression. Econometric Society Monographs.

[21] Koenker, Roger and G. Basset, 1978. Regression Quantiles. Econometrica $46,33-50$.

[22] Koenker, Roger and Q. Zhao,1996. Conditional Quantile Estimation and Inference for ARCH Models. Econometric Theory 12, 793-813.

[23] Kupiec, P., 1995. Techniques for Verifying the Accuracy of Risk Measurement Models. Journal of Derivatives 3, 73-84.

[24] Lambert, Philippe and Sébastien Laurent, 2001. Modelling Financial Time Series Using GARCH-Type Models and a Skewed Student Density. Mimeo. Université de Liège.

[25] Laurent, Sebastien and J.P. Peters, 2005. G@RCH 4.0, Estimating and Forecasting ARCH Models. Timberlake Consultants Press and Oxford, London.

[26] L'Ecuyer, Pierre, 1999. Tables of Maximally-Equidistributed Combined LFSR Generators. Mathematics of Computation 68, 261-269.

[27] Lopez, Jose A., 1999a. Regulatory Evaluation of Value-at-Risk Models. Journal of Risk 1, 37-64.

[28] Lopez, Jose A., 1999b. Methods for Evaluating Value-at-Risk Estimates. Federal Reserve Bank of San Francisco, Economic Review 2, 3-17.

[29] Marsaglia, George, 1997. A Random Number Generator for C. Discussion Paper, Posting on usenet newsgroup sci.stat.math.

[30] Marsaglia, George and A. Zaman, 1994. Some Portable Very-Long-Period Random Number Generators. Computers in Physics 8, 117-121.

[31] Matsumoto, Makoto and Takuji Nishimura, 1998. Mersenne Twister: A 623-Dimensionally Equidistributed Uniform Pseudo-Random Number Generator. ACM Transactions on Modeling and Computer Simulation 8, 3-30. 
[32] Nam, Kiseok, Kenneth M. Washer and Quantin C. Chu, 2005. Asymmetric Return Dynamics and Technical Trading Strategies. Journal of Banking \& Finance 29, 391-418.

[33] Park S. and K. Muller, 1988. Random Number Generators: Good Ones Are Hard to Find. Communications of the ACM 31, 1192-1201.

[34] Wu, G. and Zhijie Xiao, 2002. An Analysis of Risk Measures. Journal of Risk, 4, 53-75. 


\section{Últimos Ensaios Econômicos da EPGE}

[604] Pedro Cavalcanti Gomes Ferreira e Leandro Gonçalves do Nascimento. Welfare and Growth Effects of Alternative Fiscal Rules for Infrastructure Investment in Brazil. Ensaios Econômicos da EPGE 604, EPGE-FGV, Nov 2005.

[605] João Victor Issler, Afonso Arinos de Mello Franco, e Osmani Teixeira de Carvalho Guillén. The Welfare Cost of Macroeconomic Uncertainty in the Post-War Period. Ensaios Econômicos da EPGE 605, EPGE-FGV, Dez 2005.

[606] Marcelo Côrtes Neri, Luisa Carvalhaes, e Alessandra Pieroni. Inclusão Digital e Redistribuição Privada. Ensaios Econômicos da EPGE 606, EPGE-FGV, Dez 2005.

[607] Marcelo Côrtes Neri e Rodrigo Leandro de Moura. La institucionalidad del salario mínimo en Brasil. Ensaios Econômicos da EPGE 607, EPGE-FGV, Dez 2005.

[608] Marcelo Côrtes Neri e André Luiz Medrado. Experimentando Microcrédito: Uma Análise do Impacto do CrediAMIGO sobre Acesso a Crédito. Ensaios Econômicos da EPGE 608, EPGE-FGV, Dez 2005.

[609] Samuel de Abreu Pessôa. Perspectivas de Crescimento no Longo Prazo para o Brasil: Questões em Aberto. Ensaios Econômicos da EPGE 609, EPGE-FGV, Jan 2006.

[610] Renato Galvão Flôres Junior e Masakazu Watanuki. Integration Options for Mercosul - An Investigation Using the AMIDA Model. Ensaios Econômicos da EPGE 610, EPGE-FGV, Jan 2006.

[611] Rubens Penha Cysne. Income Inequality in a Job-Search Model With Heterogeneous Discount Factors (Revised Version, Forthcoming 2006, Revista Economia). Ensaios Econômicos da EPGE 611, EPGE-FGV, Jan 2006.

[612] Rubens Penha Cysne. An Intra-Household Approach to the Welfare Costs of Inflation (Revised Version, Forthcoming 2006, Estudos Econômicos). Ensaios Econômicos da EPGE 612, EPGE-FGV, Jan 2006.

[613] Pedro Cavalcanti Gomes Ferreira e Carlos Hamilton Vasconcelos Araújo. On the Economic and Fiscal Effects of Infrastructure Investment in Brazil. Ensaios Econômicos da EPGE 613, EPGE-FGV, Mar 2006.

[614] Aloisio Pessoa de Araújo, Mario R. Páscoa, e Juan Pablo Torres-Martínez. Bubbles, Collateral and Monetary Equilibrium. Ensaios Econômicos da EPGE 614, EPGE-FGV, Abr 2006. 
[615] Aloisio Pessoa de Araújo e Bruno Funchal. How much debtors' punishment?. Ensaios Econômicos da EPGE 615, EPGE-FGV, Mai 2006.

[616] Paulo Klinger Monteiro. First-Price Auction Symmetric Equilibria with a General Distribution. Ensaios Econômicos da EPGE 616, EPGE-FGV, Mai 2006.

[617] Renato Galvão Flôres Junior e Masakazu Watanuki. Is China a Northern Partner to Mercosul?. Ensaios Econômicos da EPGE 617, EPGE-FGV, Jun 2006.

[618] Renato Galvão Flôres Junior, Maria Paula Fontoura, e Rogério Guerra Santos. Foreign direct investment spillovers in Portugal: additional lessons from a country study. Ensaios Econômicos da EPGE 618, EPGE-FGV, Jun 2006.

[619] Ricardo de Oliveira Cavalcanti e Neil Wallace. New models of old(?) payment questions. Ensaios Econômicos da EPGE 619, EPGE-FGV, Set 2006.

[620] Pedro Cavalcanti Gomes Ferreira, Samuel de Abreu Pessôa, e Fernando A. Veloso. The Evolution of TFP in Latin America. Ensaios Econômicos da EPGE 620, EPGE-FGV, Set 2006.

[621] Paulo Klinger Monteiro e Frank H. Page Jr. Resultados uniformemente seguros e equilíbrio de Nash em jogos compactos. Ensaios Econômicos da EPGE 621, EPGE-FGV, Set 2006.

[622] Renato Galvão Flôres Junior. DOIS ENSAIOS SOBRE DIVERSIDADE CULTURAL E O COMÉRCIO DE SERVIÇOS. Ensaios Econômicos da EPGE 622, EPGE-FGV, Set 2006.

[623] Paulo Klinger Monteiro, Frank H. Page Jr., e Benar Fux Svaiter. Exclusão e multidimensionalidade de tipos em leilões ótimos. Ensaios Econômicos da EPGE 623, EPGE-FGV, Set 2006.

[624] João Victor Issler, Afonso Arinos de Mello Franco, e Osmani Teixeira de Carvalho Guillén. The Welfare Cost of Macroeconomic Uncertainty in the Post-War Period. Ensaios Econômicos da EPGE 624, EPGE-FGV, Set 2006.

[625] Rodrigo Leandro de Moura e Marcelo Côrtes Neri. Impactos da Nova Lei de Pisos Salariais Estaduais. Ensaios Econômicos da EPGE 625, EPGE-FGV, Out 2006.

[626] Renato Galvão Flôres Junior. The Diversity of Diversity: further methodological considerations on the use of the concept in cultural economics. Ensaios Econômicos da EPGE 626, EPGE-FGV, Out 2006.

[627] Maurício Canêdo Pinheiro, Samuel Pessôa, e Luiz Guilherme Schymura. $O$ Brasil Precisa de Política Industrial? De que Tipo?. Ensaios Econômicos da EPGE 627, EPGE-FGV, Out 2006.

[628] Fabio Araujo, João Victor Issler, e Marcelo Fernandes. A Stochastic Discount Factor Approach to Asset Pricing Using Panel Data. Ensaios Econômicos da EPGE 628, EPGE-FGV, Nov 2006. 